\title{
A Report of Rabbit Syndrome Who Benefited from Sigma 1 Agonist Fluvoxamine
}

\author{
Yakup Albayrak, Murat Beyazyüz, Özlem Abbak, Ece Altındağ \\ Department of Psychiatry, Faculty of Medicine, Namık Kemal University, Tekirdag, Turkey
}

\begin{abstract}
Rabbit Syndrome is an uncommon side effect of antipsychotic treatment. Although it is usually associated with typical antipsychotics, it can also be related to atypical antipsychotics. Anticholinergics are the most accepted treatment approach in treating Rabbit Syndrome. Fluvoxamine is a member of selective serotonin reuptake inhibitors and it is a potent agonist of sigma 1 receptors. In this article, we report a Rabbit Syndrome case who has benefited from fluvoxamine, in terms of both depressive disorder and Rabbit Syndrome; and present the data on the effects of sigma 1 agonist fluvoxamine on numerous movement disorders.
\end{abstract}

KEY WORDS: Rabbit syndrome; Sigma receptors; Side effect; Fluvoxamine.

\section{INTRODUCTION}

Fluvoxamine is a selective serotonin reuptake inhibitor (SSRI) which is used for the treatment of depressive disorder and obsessive compulsive disorder. ${ }^{1,2)}$ Besides its effect on the serotonergic system, it was well established that fluvoxamine is a potent sigma 1 chaperone receptor agonist. ${ }^{3)}$ The data on the effects of sigma 1 agonism on neuropsychiatric diseases is limited. Sigma receptor agonism has various effects on the central nervous system, as well as on other systems of body via Ca signaling, protein kinase translocation or activation, ion channel firing, neurotransmitter release, cellular differentiation, neuronal survival, and synaptogenesis. ${ }^{4-9)}$ Several therapeutic drugs, which have been used on humans, and some neurosteroids such as dehydroepiandrosterone have high to moderate sigma-1 receptor affinity. Cumulative data suggest benefits of sigma 1 agonism on neuropsychiatric diseases, however there still has not been any exact explanation which can highlight the action of mechanism. ${ }^{10)}$

Received: March 17, 2017 / Revised: June 17, 2017

Accepted: July 19, 2017

Address for correspondence: Yakup Albayrak, MD

Department of Psychiatry, Faculty of Medicine, Namik Kemal

Universitesi, Tıp Fakültesi, Kampus Cad. No:1 Tekirdag, Turkey

Tel: +90-5056355434, Fax: +90-2822509928

E-mail: dr.fuge@hotmail.com

ORCID: https://orcid.org/0000-0002-1926-1695
Although all SSRIs share the same mechanism of action by means of the serotonergic system, their effects on sigma 1 receptors vary. Among these drugs, fluvoxamine exerts the most potent agonistic activity on sigma 1 receptors. ${ }^{3,11}$ There have been experimental studies which demonstrated the effects of fluvoxamine as a potent sigma 1 receptor agonist. Furthermore, there have been clinical studies and case reports which reported the beneficial effects of fluvoxamine, by means of sigma 1 receptor agonistic activity, on numerous neuropsychiatric diseases. ${ }^{10)}$

Rabbit syndrome is a drug induced movement disorder that is particularly associated with antipsychotics. ${ }^{2)}$ It is relatively uncommon and is characterized by rhythmic movements of perioral muscles, which seems as the appearance of a chewing rabbit. It has been reported to commonly be associated with typical antipsychotics ${ }^{13)}$; however, it can also be associated with atypical antipsychotics. ${ }^{12,14)}$ Here, we report a case, who developed Rabbit syndrome after long acting risperidone treatment, and benefited from fluvoxamine in terms of both depressive symptoms and symptoms of Rabbit syndrome.

\section{CASE}

A 62-year-old man admitted to outpatient clinic with symptoms of depressive mood, anhedonia, insomnia, de-

(ㄷ) This is an Open-Access article distributed under the terms of the Creative Commons Attribution Non-Commercial License (http://creativecommons.org/licenses/by-nc/4.0) which permits unrestricted non-commercial use, distribution, and reproduction in any medium, provided the original work is properly cited. 
creased appetite, difficulty in concentration, ideas of hopelessness, psychomotor agitation, and abnormal movements of the lips. In his history, his complaints began four months ago as; being followed by strangers, hearing voices that commented and humiliated him, being unable to leave his home, a decrease of self hygiene, increase in irritability, and having some homicidal attempts to family members. The patient had been taken to a psychiatrist without his will and he had been assured to be examined by a psychiatrist.

At initial assessment, the patient was assessed with routine laboratory and toxicology examinations, brain magnetic resonance imaging, and electroencephalogram. Both physical and laboratory examination had been resulted unremarkable, thus organic etiology had been excluded. Moreover, he had scored a 26 in the mini mental status examination. The patient had been diagnosed with "brief psychotic disorder" according to Diagnostic and Statistical Manual of Mental Disorders, fifth edition $(\mathrm{DSM}-5)^{15)}$ by a psychiatrist working in another center. After his psychiatric and physical assessment, the patient had been given a treatment of olanzapine $10 \mathrm{mg} /$ day. During his first outpatient control on the fifteenth day of treatment, it had been noticed that the patient was non adherent to oral treatment and his symptoms persisted. The patient had been given $25 \mathrm{mg}$ of long acting risperidone treatment bimonthly, due to lack of adherence to oral treatment. After the fourth injection of risperidone (at the second month), the psychotic symptoms were reported to be remitted; however, abnormal movements of lips developed. Because of the remission of his initial symptoms and development of abnormal movements, the treatment of $25 \mathrm{mg}$ of long acting risperidone had been stopped. The abnormal movements of the lips were consulted with the neurology department, and the patient's neurological examination had been reported to be unremarkable. The patient had been treated with biperiden $6 \mathrm{mg} /$ day for 3 weeks, and diazepam $5 \mathrm{mg} /$ day had been added to his treatment for 5 weeks due to lack of response to biperiden treatment in terms of abnormal movements of his lips.

After these interventions, the patient admitted to our outpatient clinic at the fourth month of his treatment. In his psychiatric and physical examination, abnormal movements of lips in a vertical axis, being fine, rapid, and rhythmic, were noted additional to depressive symptoms.
Routine laboratory examination, brain magnetic resonance imaging, and other neurological assessments were unremarkable. The patient was diagnosed as major depressive disorder and medication induced movement disorder (Rabbit syndrome) according to DSM-5. Fluvoxamine $100 \mathrm{mg} /$ day was prescribed as his current treatment; whereas, biperiden and diazepam treatments were stopped. The patient was recommended to be followed up bimonthly in our outpatient clinic. In his first assessment, there was a significant improvement in symptoms of Rabbit syndrome and a moderate amelioration in depressive symptoms. The dose of fluvoxamine was increased to $200 \mathrm{mg} /$ day. After the second assessment, the patient was asymptomatic in terms of Rabbit syndrome, and there was significant improvement in depressive symptoms. During the follow-up outpatient visits, the patient was noted to be asymptomatic in terms of both Rabbit syndrome and depressive disorder.

\section{DISCUSSION}

In the present case, we reported the beneficial effect of sigma 1 agonist fluvoxamine on symptoms of Rabbit syndrome and depressive disorder. The etiology of Rabbit syndrome is unclear, and it is commonly confused with and misdiagnosed as tardive dyskinesia. ${ }^{12)}$ Due to the fact that Rabbit syndrome is commonly seen after antipsychotic treatment, the etiology has been considered to be associated with the dopaminergic system. ${ }^{16)}$ Rabbit syndrome is generally known to occur due to long-term use of typical antipsychotics with a range between 1.5\% and $4.4 \%{ }^{17)}$ Quetiapine, clozapine, olanzapine, aripiprazole, paliperidone, amisulpride, and most commonly risperidone have been reported to be associated with the development of Rabbit syndrome. ${ }^{14)}$ In terms of treatment, the most acceptable approach is using anticholinergic drugs, such as benzatropine, biperiden, trihexyphenidyl. ${ }^{12)}$ In some case reports, haloperidol, olanzapine, sulpiride, and chlorpromazine were reported to be effective in the treatment of Rabbit syndrome. ${ }^{18)}$ However, the present case is the first to demonstrate the beneficial effect of sigma 1 agonist fluvoxamine on Rabbit syndrome.

Sigma 1 receptors include 223 amino acids and as noted in the introduction section, they have been associated with many cellular functions, such as cellular redox, cellular survival, neurotransmitters release etc. ${ }^{4-9)}$ It has been 
demonstrated that sigma 1 receptors act as a chaperone, and have the ability to fix and stabilize endoplasmic reticulum proteins. Both clinical and experimental studies reported various effects of sigma 1 receptors on various systems throughout the body, such as the cardiovascular system, immune reactions, pain, liver functions, cancer proliferation, and various neuropsychiatric disorders. ${ }^{6,9,19,20)}$ Fluvoxamine has been reported to be the most potent sigma 1 receptor agonist among all SSRIs. ${ }^{3)}$ Furthermore, in a positron emission tomography study, fluvoxamine was reported to bind to sigma 1 receptors in the living human body. ${ }^{21)}$ Thus, some effects of SSRIs, particularly of fluvoxamine, are mediated with sigma 1 agonism. ${ }^{19,22-24)}$

In literature, there have been restricted numbers of papers that reported association between sigma 1 agonist fluvoxamine and movement disorders. Furuse and Hashimoto $^{25,26)}$ reported cases who developed akathisia after aripiprazole treatment and blonanserin monotherapy and whose akathisia resolved after switching to fluvoxamine monotherapy. They firstly concluded that the action mechanism of fluvoxamine for resolving akathisia might be associated with sigma 1 receptor agonism. We have also reported cases who benefited from fluvoxamine in terms of; hemiballism and depressive disorder ${ }^{27)}$; tardive dyskinesia in patients with post-psychotic depressive disorder of schizophrenia ${ }^{28)}$; duloxetine induced tardive dyskinesia ${ }^{29)}$; tardive dyskinesia in two patients with schizophrenia ${ }^{30)}$; tardive akathisia in a patient with schizophrenia $^{30)}$; and improvement of chorea. ${ }^{31)}$ There are conflicting data on the activity of sigma 1 receptors on the dopaminergic system. Sigma 1 receptor agonists can either increase or decrease dopaminergic activity via the striatal pathway of dopamine. ${ }^{24)}$ Furthermore, sigma 1 receptors are highly concentrated in the limbic and motor systems of the human brain. Sigma 1 receptors are highly existent in the putamen, septum, caudate, nucleus accumbens, and amygdala in rats and humans. Fluvoxamine can act as a dopamine regulator, particularly on the striatal pathway, in patients with movement disorder via sigma 1 agonism. ${ }^{32,33)}$ Sigma receptor agonistic activity can act to prevent neurodegeneration and inhibit excitotoxic factors. ${ }^{34)}$ Because the etiology of movement disorders such as, tardive dyskinesia, akathisia, chorea, and hemiballism are complex; it is difficult to say the exact mechanism of action of fluvoxamine. However, it can be suggested that the sigma 1 agonistic activity of fluvoxamine might mediate beneficial effects for the movement disorders mentioned above.

Anticholinergic agents such as, benzatropine, biperiden, trihexyphenidyl are accepted to be the most effective agents for the treatment of Rabbit syndrome ${ }^{12)}$; however, besides treatment, these agents can affect various systems of the body regarding cholinergic distribution of cholinergic receptors. ${ }^{35)}$ Although fluvoxamine has anticholinergic activities on the living body, it has been considered to lack specific and significant affinity on muscarinic receptors. Among antidepressants, fluvoxamine has been placed in the low anticholinergic effect class with antidepressants, such as bupropion, fluoxetine, mirtazapine, sertraline, and trazodone. ${ }^{35-37)}$ Since the most acceptable approach in the treatment of Rabbit syndrome is the use of anticholinergics, in this case a question arises that the action of mechanism of fluvoxamine might be due to its low anticholinergic effects. However, our patient had been given the treatment of biperiden and he did not benefit from it in terms of Rabbit syndrome. Thus, it may be more plausible to consider the action of mechanism from potent sigma 1 receptor agonism, rather than anticholinergic effects. From this point, sigma 1 agonist fluvoxamine, can be considered to be an alternative treatment choice for movement disorders, without the serious and uncomfortable side effects.

In conclusion, we suggest that fluvoxamine, as well as other sigma 1 receptor agonists, may be good candidates for the treatment of movement disorders. Current data about the effect of sigma 1 receptor agonism on movement disorders is restricted with case studies. Further studies are needed to highlight the role of sigma 1 receptor agonists on the treatment of movement disorders.

\section{REFERENCES}

1. Goodnick PJ, Goldstein BJ. Selective serotonin reuptake inhibitors in affective disorders-l. Basic pharmacology. J Psychopharmacol 1998;12(3 Supp/ B):S5-S2O.

2. Nemeroff CB, Owens MJ. Pharmacologic differences among the SSRIs: focus on monoamine transporters and the HPA axis. CNS Spectr 2004;9(6 Supp/ 4):23-31.

3. Ishima T, Fujita Y, Hashimoto K. Interaction of new antidepressants with sigma-1 receptor chaperones and their potentiation of neurite outgrowth in PC1 2 cells. Eur J Pharmacol 2014;727:167-173.

4. Marrazzo A, Caraci F, Salinaro ET, Su TP, Copani A, Ronsisvalle G. Neuroprotective effects of sigma-1 receptor agonists against beta-amyloid-induced toxicity. Neuroreport 
2005; 16:1223-1226.

5. Maurice T, Su TP. The pharmacology of sigma-1 receptors. Pharmacol Ther 2009;124:195-206.

6. Hayashi T, Su TP. Sigma-1 receptor ligands: potential in the treatment of neuropsychiatric disorders. CNS Drugs 2004;18: 269-284.

7. Fishback JA, Robson MJ, Xu YT, Matsumoto RR. Sigma receptors: potential targets for a new class of antidepressant drug. Pharmacol Ther 2010;127:271-282.

8. Yao H, Yang Y, Kim KJ, Bethel-Brown C, Gong N, Funa K, et al. Molecular mechanisms involving sigma receptor-mediated induction of MCP-1: implication for increased monocyte transmigration. Blood 2010;115:4951-4962.

9. Hayashi T, Tsai SY, Mori T, Fujimoto M, Su TP. Targeting /igand-operated chaperone sigma-1 receptors in the treatment of neuropsychiatric disorders. Expert Opin Ther Targets 2011; 15:557-577.

10. Albayrak Y, Hashimoto K. Clinical implications of fluvoxamine and fluoxetine with sigma-1 receptor chaperone activity in the treatment of neuropsychiatric disorders. In: Pinna $G$, editor. Fluoxetine: pharmacology, mechanisms of action and potential side effects. New York:Nova Science Pub.;2015. p.279-294.

11. Narita N, Hashimoto K, Tomitaka S, Minabe Y. Interactions of selective serotonin reuptake inhibitors with subtypes of sigma receptors in rat brain. Eur J Pharmacol 1996;307:117-119.

12. Schwartz M, Hocherman S. Antipsychotic-induced rabbit syndrome: epidemiology, management and pathophysiology. CNS Drugs 2004;18:213-220.

13. Chiu HF, Lam LC, Chung DW, Wing YK, Shum PP. Prevalence of the rabbit syndrome in Hong Kong. I Nerv Ment Dis 1993; 181:264-265.

14. Nataraj J, Jabbal R. Antipsychotic-induced rabbit syndrome in a pediatric patient. Can J Hosp Pharm 2015;68:478-480.

15. American Psychiatric Association. Diagnostic and Statistical Manual of Mental Disorders. 5th ed. Washington, D.C.: American Psychiatric Association;2013.

16. Nambu A, Tokuno H, Inase M, Takada M. Corticosubthalamic input zones from forelimb representations of the dorsal and ventral divisions of the premotor cortex in the macaque monkey: comparison with the input zones from the primary motor cortex and the supplementary motor area. Neurosci Lett 1997;239:13-16.

17. Teng PR, Lai TJ. Paliperidone-related rabbit syndrome. J Clin Psychopharmacol 2011;31:379-380.

18. Nishiyama K, Masuda N, Kurisaki H. [A case of rabbit syndrome--its unique pharmacological feature]. Rinsho Shinkeigaku 1993;33:663-665. Japanese.

19. Hashimoto K. Sigma-1 receptor chaperone and brain-derived neurotrophic factor: emerging links between cardiovascular disease and depression. Prog Neurobiol 2013;100:15-29.

20. Shirayama Y, Hashimoto K. A case of psychotic depression treated with fluvoxamine monotherapy. Clin Psychopharmacol
Neurosci 2010;8:53-54.

21. Ishikawa M, Ishiwata K, Ishii K, Kimura Y, Sakata M, Naganawa $M$, et al. High occupancy of sigma-1 receptors in the human brain after single oral administration of fluvoxamine: a positron emission tomography study using [11C] SA4503. Biol Psychiatry 2007;62:878-883.

22. Hashimoto K. Sigma-1 receptors and selective serotonin reuptake inhibitors: clinical implications of their relationship. Cent Nerv Syst Agents Med Chem 2009;9:197-204.

23. Ishikawa $M$, Hashimoto $K$. The role of sigma-1 receptors in the pathophysiology of neuropsychiatric diseases. I Recept Ligand Channel Res 2010;3:25-36.

24. Albayrak Y, Hashimoto K. Sigma-1 receptor agonists and their clinical implications in neuropsychiatric disorders. Adv Exp Med Biol 2017;964:153-161.

25. Furuse T, Hashimoto K. Fluvoxamine for aripiprazole-associated akathisia in patients with schizophrenia: a potential role of sigma-1 receptors. Ann Gen Psychiatry 2010;9:11.

26. Furuse T, Hashimoto K. Fluvoxamine for blonanserin-associated akathisia in patients with schizophrenia: report of five cases. Ann Gen Psychiatry 2010;9:17.

27. Cayköylü A, Albayrak Y, Uğurlu GK, Ekinci O. Beneficial effects of fluvoxamine for hemiballism in a patient with depressive disorder: a case report. Acta Neurol Belg 2011;111: 62-65.

28. Albayrak Y, Hashimoto K. Beneficial effects of the sigma-1 agonist fluvoxamine for tardive dyskinesia in patients with post-psychotic depressive disorder of schizophrenia: report of 5 cases. Prim Care Companion CNS Disord 2012;14:doi: 10.4088/PCC.12br01401.

29. Albayrak Y, Ekinci O. Duloxetine-associated tardive dyskinesia resolved with fluvoxamine: a case report. I Clin Psychopharmacol 2012;32:723-724.

30. Albayrak Y, Hashimoto K. Benefical effects of sigma-1 agonist fluvoxamine for tardive dyskinesia and tardive akathisia in patients with schizophrenia: report of three cases. Psychiatry Investig 2013;10:417-420.

31. Albayrak Y, Uğurlu GK, Uğurlu M, Cayköylü A. Beneficial effects of fluvoxamine for chorea in a patient with huntington's disease: a case report. Prim Care Companion CNS Disord 2012;14:doi:10.4088/PCC.12101369.

32. Gudelsky GA. Effects of sigma receptor ligands on the extracellular concentration of dopamine in the striatum and prefrontal cortex of the rat. Eur J Pharmacol 1995;286:223-228.

33. Alonso G, Phan V, Guillemain I, Saunier M, Legrand A, Anoal $\mathrm{M}$, et al. Immunocytochemical localization of the sigma(1) receptor in the adult rat central nervous system. Neuroscience 2000;97:155-170.

34. Doyle KM, Kennedy D, Gorman AM, Gupta S, Healy SJ, Samali A. Unfolded proteins and endoplasmic reticulum stress in neurodegenerative disorders. I Cell Mol Med 2011;15:2025-2039.

35. Penttilä J, Scheinin H, Syvälahti E. Measurement of anti- 
cholinergic effects of psychotropic drugs in humans. Pharmacopsychiatry 2005;38:187-193.

36. Rudolph JL, Salow MJ, Angelini MC, McGlinchey RE. The anticholinergic risk scale and anticholinergic adverse effects in older persons. Arch Intern Med 2008;168:508-513.
37. Carnahan RM, Lund BC, Perry PJ, Pollock BG, Culp KR. The Anticholinergic Drug Scale as a measure of drug-related anticholinergic burden: associations with serum anticholinergic activity. J Clin Pharmacol 2006;46:1481-1486. 